\title{
Correlation of Platelet to Lymphocyte Ratio with Presence and Severity of Metabolic Syndrome
}

\author{
Yasemin Kaya $^{1}$, Osman Bektaş ${ }^{2}$, Ahmet Kaya $^{2}$, Zeki Yüksel Günaydın ${ }^{2}$, Adil Bayramoğlu $^{2}$, Mustafa \\ Kerem Çalgın ${ }^{3}$ \\ ${ }^{1}$ Ordu University Medical School, Department of Internal Medicine, Ordu, Turkey \\ ${ }^{2}$ Ordu University Medical School, Department of Cardiology, Ordu, Turkey \\ ${ }^{3}$ Ordu University Medical School, Department of Microbiology, Ordu, Turkey
}

Received: 01 November 2015 accepted: 24 November 2015/ published online: 24 December 2015

(C) Ordu University Institute of Health Science, Turkey, 2015

\begin{abstract}
Objective: The aim of this study is to evaluate the relation between the components of Metabolic syndrome (MS) and the inflammation and the platelet-to-lymphocyte ratio (PLR) recognized as a novel marker of pro-thrombotic state.

Method: 70 patients with MS criteria were included in the study. 70 healthy people with matching age and gender characteristics were included in the study as the control group. The patients were divided into three groups with regard to the number of MS characteristics: Group 1 (the patients with three MS criteria), group 2 (the patients with four MS criteria), and group 3 (the patients with five MS criteria). PLR was calculated in regard to the complete blood count.

Results: The patients with MS had significantly higher PLR level compared to those without MS. However, PLR level were not associated with severity of MS. A moderate positive correlation was revealed between the severity of MS and PLR $(r=0.419, \mathrm{p}<0.001)$ and a strong positive correlation between the severity of MS and hs-CRP ( $\mathrm{r}=0.562$, $\mathrm{p}<0.001)$. Also, a positive correlation was detected between hs-CRP and PLR in our patient population ( $r=0.281$, $\mathrm{p}=0.002$ ). In order to specify the level of PLR to predict MS, ROC curve analysis was performed. The cut-off level for PLR with optimal sensitivity and specificity was calculated as 0,132 (Area under curve [AUC] $=0.744$ [0.655-0.833], $\mathrm{p}<0.001)$. For that level, the sensitivity was $73 \%$ and the specificity was $68,4 \%$.

Conclusion: This is the first study which determines the fact that there is a relation between MS criteria, the inflammation and PLR, which is a new marker of the pro-thrombotic state. There is also a positive correlation between PLR and hs-CRP in these patients. PLR may be beneficial in predicting the adverse cardiovascular cases in the patients with MS.

Key words: Metabolic Syndrome, Platelet/lymphocyte ratio, Inflammation

Address for correspondence/reprints:

Yasemin KAYA

Telephone number: +90 4522252342

E-mail: ysmnkcmz@gmail.com

DOI: $10.19127 /$ mbsjohs. 32758

\section{Introduction}

Metabolic syndrome (MS) is a case basically beginning with insulin resistance (IR), containing a combination of the systemic disorders such as abdominal obesity, glucose intolerance or diabetes mellitus, dyslipidemia, hypertension and coronary artery disease (CAD), and accompanied by vascular inflammation and pro-thrombotic tendency. The prevalence of metabolic syndrome increases with the increased physical inactivity and the central obesity in our society (Bloomgarden, 2003). MS includes more than one risk factor in terms of cardiovascular diseases. IR, which is one
\end{abstract}


of the basic pathological mechanisms composing MS, is related to especially proinflammatory and pro-thrombotic state (Calles-Escandon et al., 1998 and Hori et al., 2005). Pro-thrombotic and proinflammatory tendency has an important role in the exacerbation of the atherosclerotic process and the formation of serious clinical states.

The studies carried out demonstrate the relation between the components of MS and the tendency to proinflammatory state. A simple indicator of proinflammatory state in the patients with MS is the detection of the increased $\mathrm{C}$ - reactive protein (CRP) in these patients. It is additionally known that the levels of interleukin-6 (IL-6) and tumor necrosis factor alpha (TNF- $\alpha$ ) increase in these patients (Yudkin et al., 1999). Inflammation is known to have a role in the onset and the progress of atherosclerotic illnesses (Hansson et al., 2005). Platelet-to-lymphocyte ratio (PLR) has recently been identified as a biological indicator of the balance between inflammation and thrombosis especially in the patients with malignancy (Smith et al., 2008; Wang et al., 2013). There are evidences about the negative consequences of the increase in PLR in the cardiovascular diseases (Azab et al., 2012; Acar et al., 2013). The aim of this study is to assess the relationship between MS, its components and PLR, which has recently been recognized as an inflammation and pro-thrombotic indicator.

\section{Materials and Methods}

In a retrospective longitudinal study, our study population consisted of non-selected 194 patients, who visited our clinic from January to August. The exclusion criteria were determined as infection $(\mathrm{n}: 4)$, chronic systemic inflammatory diseases (n:5) and the patients using drug affecting the number of leukocytes (steroid, chemotherapeutic etc.) (n:3). Also, the patients with renal failure $(\mathrm{n}: 6)$, liver failure $(\mathrm{n}: 3)$, secondary hypertension $(\mathrm{n}: 16)$ and known coronary artery disease (n:9), heart failure (n:7), and severe heart valve diseases $(n: 4)$ were excluded from the study. Finally, the study population consisted of 140 patients (n:70 patients who had metabolic syndrome, n:70 ageand sex-matched healthy subjects). All participants gave an informed consent and the study was approved by the local ethics committee.

For the diagnosis of MS, National Cholesterol Education Program Adult Treatment Panel III criteria (NCEP ATP 3) were used (Adult Treatment
Panel III, 2001) The presence of 3 or more criteria below was accepted as MS.

1- Hypertension: Existing antihypertensive therapy or blood pressure $\geq 130 / 85 \mathrm{~mm} / \mathrm{Hg}$

2- Dyslipidemia: Plasma triglyceride (TG) level $\geq 150 \mathrm{mg} / \mathrm{dL}(\geq 1.7 \mathrm{mmol} / \mathrm{L})$

3- Low HDL cholesterol level: In women $<50$ $\mathrm{mg} / \mathrm{dL}(<1.3 \mathrm{mmol} / \mathrm{L})$, in men $<40 \mathrm{mg} / \mathrm{dl}(<1.0$ $\mathrm{mmol} / \mathrm{L})$

4- Abdominal Obesity: Waist circumference (WC) in men $>102 \mathrm{~cm}$, WC in women $>88 \mathrm{~cm}$

5- Glucose: Fasting blood glucose $\geq 110 \mathrm{mg} / \mathrm{dL}$ ( $\geq 5.6 \mathrm{mmol} / \mathrm{L}$ ) Type $2 \mathrm{DM}$ or impaired glucose tolerance test.

The patients were divided into three groups with regard to the number of MS characteristics: Group 1 (the patients with three MS criteria), group 2 (the patients with four MS criteria), and group 3 (the patients with five MS criteria).

Blood Pressure (BP) was measured after at least 15-minute rest in sitting position. The mean of all three measurements with five-minute intervals were considered as BP. High sensitive C-Reactive protein (hs-CRP), total cholesterol, TG, HDL, LDL levels, urea, creatinine and plasma glucose were measured in the venous blood samples obtained in the morning after eight-hour fasting. The complete blood count was studied in our hematology unit with Beckman-Coulter Gen-S system device (Beckman-Coulter Inc., USA). The weight, height, and WC were measured while fasting and standing up by the standard measuring tools. The narrowest diameter between costal arch and anterior superior iliac spine was measured for WC. Body mass index (BMI) $\left(\mathrm{kg} / \mathrm{m}^{2}\right)$ and body surface area (BSA) $\left(\mathrm{m}^{2}\right)$ were calculated using the formulas "weight $(\mathrm{kg}) /$ height $(\mathrm{m})^{2}$ " and "BSA $\left(\mathrm{m}^{2}\right)=0.007184 \mathrm{x}$ Height $(\mathrm{cm})^{0.725} \mathrm{x}$ Weight $(\mathrm{kg})^{0.425 "}$ respectively.

\section{Statistical analysis:}

Independent sample $t$ test or Mann-Whitney $U$ test were used for continuous variables, and chisquare test for categorical variables. One-way analysis of variance (ANOVA) or Kruskal-Wallis tests were used to compare more than two groups. Correlations were assessed using Spearman's test. Receiver operating characteristic (ROC) curve analysis was used to determine the optimum cutoff level of PLR to predict the metabolic syndrome. Statistical analyses were performed using Statistical Package for Social Sciences (SPSS) Version 15.0 (SPSS Inc., Chicago, Illinois). Continuous variables 
were defined as mean \pm standard deviation, and categorical variables were given as percentages. Any $P$ value $<0.05$ was considered as statistically significant.

\section{Results}

70 patients with MS and 70 people with matching age and gender as the control group were included in the study. The characteristics of two groups were summarized in Table 1. As showed in Table 2, while the number of neutrophils, white blood cells (WBC) and lymphocyte were higher in the patients with MS than the control group, the platelet count and the hemoglobin level were found similar.

Table-1: Differences between clinical and laboratory parameters of the groups with and without metabolic syndrome

\begin{tabular}{|c|c|c|c|}
\hline & MS (-) & MS (+) & P value \\
\hline Age (years) & $47,0 \pm 13,7$ & $48,3 \pm 9,51$ & 0,542 \\
\hline WC & $85,75 \pm 10,9$ & $97,8 \pm 10$ & $<0,001$ \\
\hline BMI (kg/m²) & $24,5 \pm 3,92$ & $29,2 \pm 5,51$ & $<0,001$ \\
\hline $\begin{array}{l}\text { FBG } \\
(\mathrm{mmol} / \mathrm{L})\end{array}$ & $5,0 \pm 0,77$ & $6,2 \pm 1,48$ & $<0,001$ \\
\hline TG (mmol/L) & $1,46 \pm 0,56$ & $2,38 \pm 1,12$ & $<0,001$ \\
\hline $\begin{array}{l}\text { HDL } \\
(\mathbf{m m o l} / \mathbf{L})\end{array}$ & $1,23 \pm 0,20$ & $0,95 \pm 0,22$ & $<0,001$ \\
\hline $\begin{array}{l}\text { LDL } \\
(\mathrm{mmol} / \mathrm{L})\end{array}$ & $2,7 \pm 0,84$ & $3,00 \pm 0,59$ & 0,028 \\
\hline SBP (mmHg) & $129 \pm 15,7$ & $134 \pm 18,8$ & 0,086 \\
\hline DBP (mmHg) & $81,1 \pm 10,45$ & $85,3 \pm 9,72$ & 0,024 \\
\hline \multicolumn{4}{|c|}{$\begin{array}{l}\text { MS: Metabolic syndrome, WC: Waist Circumference, BMI: } \\
\text { Body Mass Index, FBG: Fasting Blood Glucose, TG: } \\
\text { Triglycerides, DL: High Densty lipoprotein, LDL: Low } \\
\text { Densty lipoprotein, SBP: Systolic Blood Pressure, DBP: } \\
\text { Diastolic Blood Pressure }\end{array}$} \\
\hline
\end{tabular}

Table-2: The hematologic parameters of the groups with and without metabolic syndrome

\begin{tabular}{lccc}
\hline & MS (-) & MS (+) & P value \\
\hline $\begin{array}{l}\text { WBC } \\
\text { Hemoglobin } \\
(\text { g/dL) }\end{array}$ & $6560 \pm 983$ & $7150 \pm 1442$ & 0,010 \\
PLR & $13,5 \pm 0,5$ & $13,5 \pm 0,50$ & 0,562 \\
$\begin{array}{l}\text { Platelet count } \\
(\times \mathbf{1 0 0 0})\end{array}$ & $282,6 \pm 66,3$ & $288,1 \pm 67,7$ & 0,653 \\
$\begin{array}{l}\text { Lymphocyte } \\
\text { Count }\end{array}$ & $2431 \pm 551$ & $1823 \pm 501$ & $<0,001$ \\
$\begin{array}{l}\text { Neutrophil } \\
\text { Count }\end{array}$ & $3984 \pm 817$ & $5182 \pm 1171$ & $<0,001$ \\
Hs-CRP & $0,65 \pm 0,33$ & $1,12 \pm 0,49$ & $<0,001$ \\
\hline
\end{tabular}

MS: Metabolic Syndrome, WBC: White Blood Cells, PLR: Platelet to Lymphocyte Ratio, Hs-CRP: High sensitive-C reactive protein
Also, hs-CRP level was significantly higher in MS group than the control group $(1.15 \pm 0.52$ vs $0.64 \pm 0.34, p<0.001$ ). (Figure-1).

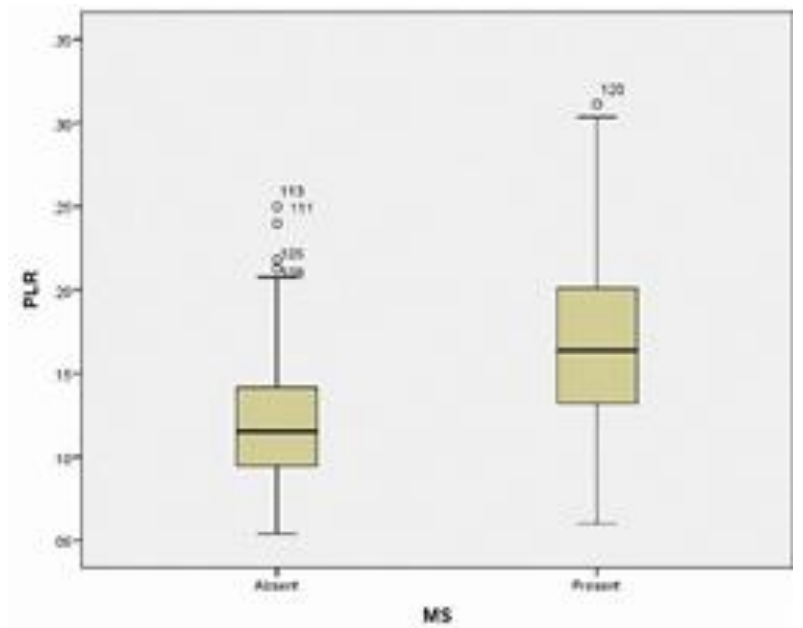

Figure-1: PLR values according to MS

The patients with MS had significantly higher PLR level compared to those without MS. However, PLR level were not associated with severity of MS (Figure 2).

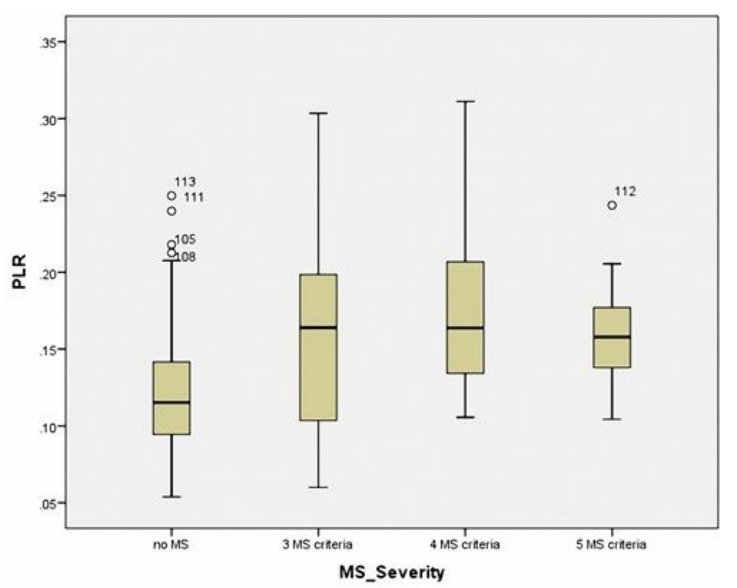

Figure-2: PLR values according to MS severity

A moderate positive correlation was revealed between the severity of MS and PLR ( $\mathrm{r}=0.419$, $\mathrm{p}<0.001)$ and a strong positive correlation between the severity of MS and hs-CRP $(r=0.562, \mathrm{p}<0.001)$ was found (Figure 3 and 4). 


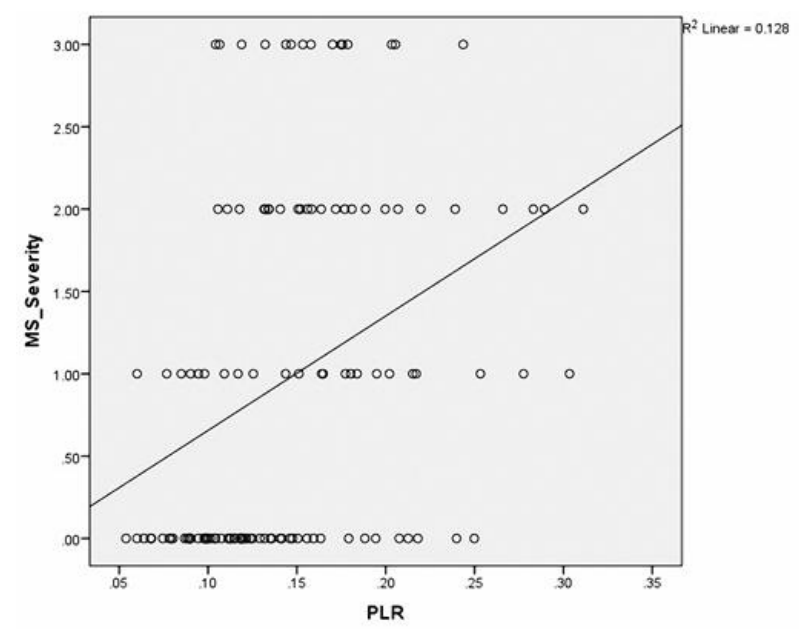

Figure-3: Correlations of MS severty with PRL

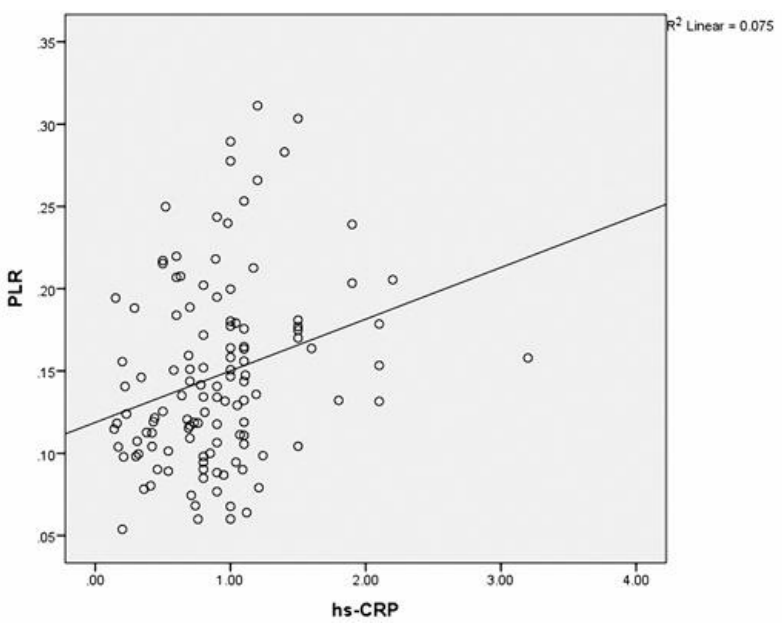

Figure-4: Correlations of PRL with hs-CRP

Also, a positive correlation between hs-CRP and PLR was detected in our patient population $(\mathrm{r}=0.281, \mathrm{p}=0.002)$. In the subjects without MS, PLR was detected to be significantly lower compared to those with MS meeting three, four, and five criteria $(0,12 \pm 0,04$ vs $0,16 \pm 0.06$, $0,18 \pm 0.06$, and $0,16 \pm 0.04)$. However, there were no differences between the patients meeting three, four and five MS criteria $(0,16 \pm 0.06,0,18 \pm 0.06$, and $0,16 \pm 0.04$, three vs four p:0,169, three vs five $\mathrm{p}: 0,963$, four vs five $\mathrm{p}: 0.241$ ).

In order to specify the level of PLR to predict MS, ROC curve analysis was performed. The cut-off level for PLR with optimal sensitivity and specificity was calculated as 0,132 (Area under curve $[\mathrm{AUC}]=0.744[0.655-0.833], \mathrm{p}<0.001)$. For that level, the sensitivity was $73 \%$ and the specificity was $68,4 \%$ (Figure 5).

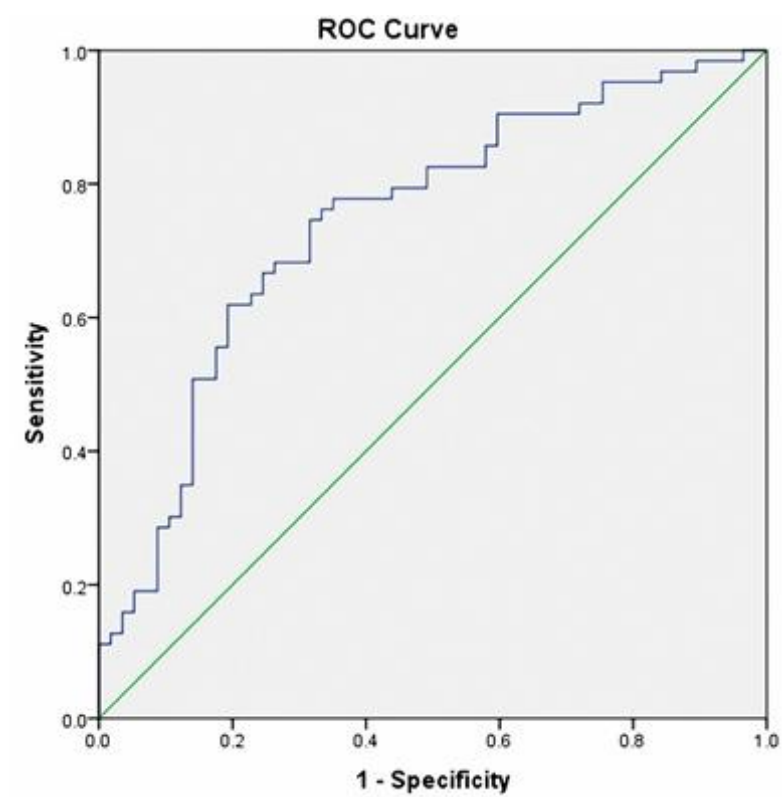

Figure-5: Receiver-operating characteristic (ROC) curve analysis plot to determine the cutoff value of PRL in MS

\section{Discussion}

As a summary of the results of this study; firstly, an important correlation between the inflammation and PLR, which was recognized as an indicator pf pro-thrombotic progress, was detected. Secondly, there was no correlation between the increase in PLR and the increase in the number of MS criteria. Thirdly, a significant relation between PLR and hs-CRP level associated with inflammation in the patients with MS was detected. The data obtained in this study about the relation between PLR and MS is the first findings in the Literature.

MS arises from the combination of the metabolic sourced risk factors increasing the development of atherosclerosis, and is a metabolic disorder based on IR (Moreno et al., 2004). The classical components of MS are the increased BP, atherogenic dyslipidemia, glucose intolerance, central obesity, vascular inflammation and prothrombotic state. These components demonstrate the treatment goals in addition to the diagnosis of metabolic (Bloomgarden, 2003). The relation of almost all of MS components with the systemic inflammation was presented (Fröhlich et al., 2000). The simplest indicator of the increased proinflammatory state in the patients with MS is the increased C-reactive protein level. Moreover, as the number of MS components increases, the amount of C-reactive protein increases, too. The increased $\mathrm{C}$-reactive protein amount is related to the increased cardiovascular cases (Ridker et al., 
2003). This causes to think that both diabetes mellitus and atherosclerosis may be related to the inflammation (Haffner et al., 2006).

In the case of obesity, proinflammatory and proatherogenic cytokines, one of the criteria composing MS, such as IL- 6 , TNF- $\alpha$, resistin, visfatin, the omentum, leptin, plasminogen activator inhibitor $-1(\mathrm{PAI}-1)$ and many bioactive adipokinine are released from the increased adipose fat tissue (Mazurek et al., 2003; Baker et al., 2006; Fain et al., 2008). IL-6 level, one of these inflammatory cytokines increases in parallel with the fat tissue, and IL-6 also induces the production of $\mathrm{C}$-reactive protein. The numerous inflammatory cytokines released from the adipose tissue such as TNF- $\alpha$ and IL-6 induce the inflammatory activity, an important part of the atherosclerotic process (Chan et al., 2005). PLR is an important inflammatory marker found in the recently performed studies; and it was detected to be related to the major negative cardiovascular cases (Azab et al., 2012).

The hyperglycemic state consisted as a result of IR leads to the abnormalities in the coagulation system, and causes to the pro-thrombotic environment at the result of the platelet dysfunction and the generation of thrombin (Desouza et al., 1999). One of the best indicators of the pro-thrombotic state in the patients with MS is the increased PAI-1 and the fibrinogen level in the patients with obesity. The fibrinogen reflects the inflammatory activity as an acute phase reactant, and as well as is recognized as one of the new risk factors (Ross et al., 1999). This increases the tendency to the generation of thrombus leading to the development of acute coronary cases. It is a fact known for a long-term that the platelet activation and the aggregation have a role in the pathophysiology of acute coronary syndromes (Vaughan et al., 2002). For example; there is a correlation between the mean platelet volume (MPV) and the functional status of platelets. In many studies, it was showed that MPV was higher in the patients with CAD and acute coronary syndrome in proportion to the normal individuals (Kishk et al., 1985; Bath et al., 1996). Moreover, MPV was detected to be an independent indicator of reperfusion and mortality (Huczek et al., 2005). Therefore, the platelet activation has an important role in the onset and the progress of atherosclerosis (Tsiara et al., 2003). On the other side, there are studies suggesting that the low number of lymphocytes composing PLR in peripheral blood lymphocytes composing PLR in peripheral blood is related to the major cardiac negative cases (Ommen et al., 1997; Acanfora et al., 2001). Thus, PLR is recognized as a new marker compounding both two hematological parameters, and has been detected to be related to some major negative cardiovascular cases in a certain number of recent studies. It was also detected that the high level of PLR was an indicator of long-term mortality in non-ST elevation myocardial infarction (Azab et al., 2012).

This is the first study about this subject performed in the patients with MS although there are previous studies determining the relationship between PLR and the negative cardiovascular cases. The high PLR in the patients with MS may be the beginning and the predictor of the increased procoagulant and proinflammatory state, and may be the preview of the adverse cardiovascular events in these patients.

\section{Limitations}

The most important limitation of the study is the low number of the patients included in the study. The second one is to make the assessment supposing that each component of MS has the same effect. It could be more beneficial to evaluate the individual differences of the components of MS and to analyze their relations with PLR one by one. But, this could not be performed as the patient number was insufficient for the subgroup analysis.

\section{Conclusion}

This study is the confirmation of the existence of the increased inflammation in the patients with MS by PLR which is a new marker. This study is important from the clinical view as it suggests that PLR may be used in predicting the adverse cardiovascular cases in the patients with MS and the beginning of the cardiovascular disease development. 
Informed Consent: Verbal informed consent was obtained from patients who participated in this study

Peer-review: Externally peer-reviewed.

Author Contributions: Concept YK.; Design AK.; Supervision AK.; Materials YK,AK; Data Collection and/or Processing YK, OB, ZYG, AB.; Analysis and/or Interpretation ZYG; Literature Review MKÇ OB; Writing OB; Critical Review YK

Conflict of Interest: No conflict of interest was declared by the authors.

Financial Disclosure: The authors declared that this study hasn't received any financial support.

\section{References}

Acanfora D, Gheorghiade M, Trojano L, Furgi G, Pasini E, Picone C, et al. Relative lymphocyte count: a prognostic indicator of mortality in elderly patients with congestive heart failure. Am Heart J 2001; 142: 167-73.

Acar G, Kalkan ME, Avci A, Alizade E, Tabakci MM, Toprak $\mathrm{C}$ et al. The Relation of PlateletLymphocyte Ratio and Coronary Collateral Circulation in Patients With Stable Angina Pectoris and Chronic Total Occlusion. Clin Appl Thromb Hemost 2013. doi: 10.1177/1076029613508599

Azab B, Shah N, Akerman M, McGinn JT Jr. Value of platelet/lymphocyte ratio as a predictor of all-cause mortality after non-STelevation myocardial infarction. $\mathrm{J}$ Thromb Thrombolysis 2012; 34: 326-34.

Baker AR, Silva NF, Quinn DW, Harte AL, Pagano D, Bonser RS et al. Human epicardial adipose tissue expresses a pathogenic profile of adipocytokines in patients with cardiovascular disease. Cardiovasc Diabetol 2006; 5: 1-7.

Bath PM, Butterworth RJ. Platelet size: measurement, physiology and vascular disease. Blood Coagul Fibrin. 1996; 7: 157-61.

Bloomgarden ZT. American Association of Clinical Endocrinologists (AACE) consensus conference on the insulin resistance syndrome. Diabetes Care 2003; 26: 1297-303.
Calles-Escandon J, Mirza SA, Sobel BE, Schneider DJ. Induction of hyperinsulinemia combined with hyperglycemia and hypertriglyceridemia increases plasminogen activator inhibitor 1 in blood in normal human subjects. Diabetes 1998; 47: 290-3.

Chan DC, Watts GF, Ng TW, Uchida Y, Sakai $\mathrm{N}$, Yamashita $\mathrm{S}$ et al. Adiponectin and other adipocytokines as predictors of markers of triglyceride-rich lipoprotein metabolism. Clin Chem 2005; 51: 578-85.

Desouza C, Pendergrass M, Fonseca V. The insulin resistance syndrome and its vascular complications. Am J Caridol. 1999;32:16-20.

Executive Summary of the Third Report of the National Cholesterol Education Program (NCEP) Expert Panel on the Detection, Diagnosis, and Treatment of High Cholesterol in Adults: (Adult Treatment Panel III). JAMA 2001; 285: 2486-97.

Fain JN, Sacks HS, Buehrer B, Bahouth SW, Garrett E, Wolf RY et al. Identification of omentin mRNA in human epicardial adipose tissue: comparison to omentin in subcutaneous, internal mammary artery periadventitial and visceral abdominal depots. Int J Obes. 2008; 32: 810-815.

Fröhlich M, Imhof A, Berg G, Hutchinson WL, Pepys MB, Boeing $\mathrm{H}$ et al. Association between $\mathrm{C}$-reactive protein and features of the metabolic syndrome. Diabetes Care 2000; 23: 1835-9.

Haffner SM. The metabolic syndrome: Inflammation, diabetes mellitus, and cardiovascular disease. Am J Cardiol 2006; 97 : 3-11.

Hansson GK. Inflammation, atherosclerosis, and coronary artery disease. N Engl J Med 2005; 352: 1685-95.

Hori Y, Nakatani K, Morioka K, Katsuki A, Gabazza EC, Yano Y et al. Insulin enhanced thrombin-activable fibrinolysis inhibitor expression through PI3 kinase/Akt pathway. Int J Mol Med 2005;15: 265-8.

Huczek Z, Kochman J, Filipiak KJ, Horszczaruk GJ, Grabowski M, Piatkowski Ret al. Mean platelet volume on admission predicts impaired reperfusion and long-term mortality in acute myocardial infarction treated with primary percutaneous coronary intervention. J Am Coll Cardiol 2005; 46: 284-90. 
Kishk YT, Trowbridge EA, Martin JF. Platelet volume subpopulations in acute myocardial infarction: an investigation of their homogeneity for smoking, infarct size and site. Clin Sci 1985; 68: 419-25.

Mazurek T, Zhang L, Zalewski A, Mannion JD, Diehl JT, Arafat $\mathrm{H}$ et al. Human epicardial adipose tissue is a source of inflammatory mediators. Circulation 2003; 108: 2460-2466.

Moreno PR, Fuster V. New aspects in the pathogenesis of diabetic atherothrombosis. J Am Coll Cardiol 2004; 44: 2293-300.

Ommen SR, Gibbons RJ, Hodge DO, Thomson SP.. Usefulness of the lymphocyte concentration as a prognostic marker in coronary artery disease. Am J Cardiol 1997; 79: 812-4.

Ridker PM, Buring JE, Cook NR, Rifai N. Creactive protein, the metabolic syndrome, and risk of incident cardiovascular events. Circulation. 2003; 107: 391-7.

Ross R. Atherosclerosis: an inflammatory disease. N Engl J Med. 1999; 340: 115-126.

Smith RA, Ghaneh P, Sutton R, Raraty M, Campbell F, Neoptolemos JP. Prognosis of resected ampullary adenocarcinoma by preoperative serum CA199 levels and plateletlymphocyte ratio. J Gastrointest Surg 2008; 12: 1422-8.

Tsiara S, Elisaf M, Jagroop IA, Mikhailidis DP. Platelets as predictor of vascular risk: is there a practical index of platelet activity? Clin Appl Thromb Hemost. 2003; 9: 17790.

Vaughan DE. PAI-1 and cellular migration: dabbling in paradox. Arterioscler Thromb Vasc Biol. 2002; 22: 1522-3.

Wang D, Yang JX, Cao DY, Wan XR, Feng FZ, Huang HF et al. Preoperative neutrophillymphocyte and platelet-lymphocyte ratios as independent predictors of cervical stromal involvement in surgically treated endometrioid adenocarcinoma. Onco Targets Ther. 2013; 6: 211-6.

Yudkin JS, Stehouwer CD, Emesis JJ, Coppack SW. C-reactive protein in healthy subjects; associations with obesity, insulin resistance, and endothelial dysfunction. Arterioscler Thromb Vasc Biol. 1999; 19: 972-8.

for smoking, infarct size and site. Clin Sci 1985; 68: 419-25.

Potter PA, Perry AG. Basic Nursing: Essentials For Practice.5th Ed.,St. Louis: Mosby. 2003.
Profetto- Mc Grath J. The relationship of critical thinking skills and critical thinking dispositions of baccalaurate nursing students. Journal of Advanced Nursing 2003; 43: 569- 577.

Riddell T. Critical assumptions; thinking critically about critical thinking. Journal of Nursing Education 2007; 46: 121-127.

Senita J. The use of concept maps to evaluate critical thinking in the clinical setting. Teaching and Learning in Nursing 2008; 3: 6-10.

Shin KR. Critical thinking ability and clinical decision-making skills among senior nursing students in associate and baccalaureate programmes in Korea. Journal of Advanced Nursing 1998; 27: 414-421.

Shin KR, Lee JH, Ha JY, Kim KH. Critical thinking dispositions in baccalaurate nursing students. Journal of Advanced Nursing 2006; 56: 182-189.

Stewart S, Dempsey LF. A longitudinal study of baccalaureate nursing students' critical thinking dispositions. journal of nursing education 2005; 44: 81-84.

Suliman WA, Halabi J. Critical thinking, selfesteem and state anxiety of nursing students. Nurse Education Today 2007; 27: 162-168.

Sulliman WA. Critical thinking and learning styles of students in conventional and accelerated. İnternational Nursing Reviews 2006; 53: 73-79.

Tutuk A, Al D, Doğan S. Determination of the nursing students communication skills and empathy. Republic University Journal of School of Nursing 2002; 6.

Walsh CM, Hardy NC. Dispositional differences in critical thinking related to gender and academic major. J Nurs Educ 1999; 38: 149-55. 